\title{
Dossiê
}

\section{Inclusão escolar: olhares especiais}

\section{Apresentação}

Este dossiê discute a educação inclusiva no Brasil, a partir de olhares especiais de pesquisadores, professores, legisladores e escritores literários. A coletânea de treze artigos, uma entrevista e uma resenha, que se seguem, demonstram como as diretrizes nacionais para a educação especial na educação básica vêm sendo analisadas, problematizadas e efetivadas, segundo essa compreensão sintetizada na Resolução CNE/CEB n. 2/2011, Artigo 30:

Por educaçáo especial, modalidade da educaçáo escolar, entende-se um processo educacional definido por uma proposta pedagógica que assegure recursos e serviços educacionais especiais, organizados institucionalmente para apoiar, complementar, suplementar e, em alguns casos, substituir os serviços educacionais comuns, de modo a garantir a educaçáo escolar e promover o desenvolvimento das potencialidades dos educandos que apresentam necessidades educacionais especiais, em todas as etapas e modalidades da educação básica.

De modo geral, o entendimento suscitado por esse dispositivo constitucional é semelhante ao defendido pelos autores. Em seus relatos sobre investigaçóes científicas e experiências pessoais e profissionais, deixam claro suas convicçóes de que, independentemente de raça, credo, cor, idade e gênero, com limitaçôes físicas, neurológicas e psicológicas ou não, o direito de integração, participação e permanência na vida escolar formal com vistas à promoçáo do desenvolvimento cognitivo e intelectual que corrobora a superação das barreiras sociais é um direito inalienável de todos os seres humanos. 
Portanto, neste dossiê, os leitores poderáo identificar conceitos e práticas acerca das necessidades educacionais especiais sob as perspectivas de que incluir não é fazer com que os diferentes fiquem semelhantes aos demais, mas compreender que há pessoas com características definitivamente não análogas às de outras, que têm maneiras particulares de perceber e de conduzir suas próprias vidas; e de que priorizar um aprendizado é fazer com que ele se adiante ao desenvolvimento, ao que está intrinsecamente faltando no próprio desenvolvimento, e apostar na superaçáo das deficiências inatas, valorizando e potencializando qualquer rudimento de pensamento abstrato que ainda possa existir. Enfim, encontraráo argumentos conclusivos de que todas as pessoas com suas características físicas e psíquicas singulares devem ser consideradas como um indivíduo único que constrói e congrega uma sociedade, um sujeito que quer ir ao supermercado, à igreja, à escola e outros ambientes não só por direito ou aceitação, mas por vontade própria e desejo de humanização!

No artigo intitulado "Formação de professores na perspectiva da inclusão escolar da pessoa com deficiência: um estudo bibliográfico", Natália Macedo Nunes utiliza "o materialismo dialético" como paradigma para identificar as competências necessárias ao profissional que trabalha com a inclusão e, assim, "apresenta princípios que norteiam a formação profissional, destaca fatores que influenciam a forma como a inclusão é pensada, investiga a relação da inclusão com a Educação Física e, finalmente, descreve alguns desafios encontrados pela inclusão nas instituiçôes escolares".

Em "Educação inclusiva: do paradigma da igualdade para o paradigma da diversidade", Claudia S. G. Barreto e Marlene Barbosa de Freitas Reis discutem os atuais projetos de formação docente, que "apresentam uma estrutura aligeirada dos conhecimentos que possibilitam ao docente vislumbrar um contexto mais amplo de conteúdos voltados para a grande diversidade que constitui o processo educacional numa perspectiva inclusiva", e apontam perspectivas para a efetivação de uma educação inclusiva por meio da valorização do profissional da educação e o respeito à diversidade humana.

A partir de pesquisas bibliográficas, observaçôes do aluno no ambiente escolar e familiar, e entrevistas com professores regentes, pais e equipe multidisciplinar, no artigo "Atendimento Educacional Especializado: uma nova proposta de educação inclusiva", Cláudia Valente Cavalcante problematiza o AEE, uma Política Nacional de Educação Especial na Perspectiva da Educação Inclusiva publicada pelo Ministério da Educação (MEC) em 
2008 que, segundo afirma, "inaugura um novo marco legal, teórico e organizacional da educação pública brasileira”.

Também Kátia Silva Santos e Ana Carolina Christofari discutem questóes relacionadas ao mesmo tema, no artigo "O Atendimento Educacional Especializado: significados e configurações possíveis nas redes municipais de ensino de Vitória da Conquista-BA e de Porto Alegre-RS”, e concluem que "é preciso perceber em que sentidos esses dispositivos vêm alterando as práticas da escola e os modos de perceber os alunos e o processo de aprendizagem".

O artigo "Um computador por aluno: o Projeto Político-Pedagógico das escolas", de Silvana Donadio Vilela Lemos, é o resultado da primeira etapa do projeto de pesquisa intitulado "A Sala de Aula no Século XXI: Inovação e Criticidade", aprovado pelo Programa Nacional de Pós-Doutorado (PNPD), 2010, edital n. 001/2010 (MEC/CAPES e MCT/CNPq/ FINEP), que incentiva o participante a realizar uma pesquisa documental sobre a integração das TIC ao currículo da educaçáo básica, no Projeto Político-Pedagógico das escolas.

Em "Metodologia Cedet: caminhos para desenvolver potencial e talento", Zenita C. Guenther apresenta uma visão das dificuldades inerentes à área de pesquisa em educação especial para alunos dotados e talentosos, e fornece uma orientação para a organização de um plano individual de trabalho, a ser elaborado semestralmente com cada aluno.

No artigo "A escola da prisão como espaço de dupla inclusão: no contexto e para além das grades”, Elenice Maria Cammarosano Onofre apresenta dados sustentando a argumentação de que, "apesar de tolhido em sua individualidade, despido do pertencimento à sociedade, duplamente excluído - pelo analfabetismo e pelo estigma por ter passado pela universidade do crime -, o processo de escolarizaçáo do homem aprisionado afigura-se como possibilidade de construçáo da identidade perdida e do resgate da cidadania, que a privação da liberdade confere ao homem que teve sua trajetória de vida marcada pela passagem na sociedade dos cativos".

Para Edson Silva, em seu artigo que leva o título "Povos indígenas e o ensino: reconhecendo o direito à inclusão das sociodiversidades no currículo escolar com a Lei n. 11.645/2008”, o respeito aos povos indígenas e o reconhecimento das sociodiversidades no Brasil só serão possíveis a partir da implantação de dispositivos legais que cuidem dessas questôes. 
No artigo "Inclusão de alunos com deficiência nas aulas de Educação Física dos colégios de aplicação: a perspectiva de seus professores", Régis Henrique dos Reis Silva, Thiago Vaz Santiago e Sônia Bertoni analisam a situação vivenciada em seus ambientes de trabalho e constatam "que os atendimentos dos CAP/IFES às PD estáo distante daquilo que preconizam as políticas nacionais de educação especial, haja vista que não estão garantidas as condiçóes mínimas de permanência dessas pessoas naqueles colégios, mais precisamente nas aulas de Educação Física”.

Os últimos quatro artigos deste dossiê tratam de diferentes questóes relacionadas à educação especial de surdos no Brasil. Com o intuito de discutir ideias a respeito da escola inclusiva e da educação bilíngue para pessoas surdas, em artigo intitulado "Inclusão e educação de surdos: uma discussão necessária", Claudia Regina Vieira aborda "alguns problemas na educação dispensada aos alunos surdos, a tendência atual para o ensino desses sujeitos na escola inclusiva e a legislação recente que estabelece a obrigatoriedade da abordagem bilíngue".

Em "A Língua Brasileira de Sinais como inclusão social dos surdos no sistema educacional", Leonarlley Rodrigo Silva Barbosa argumenta que a inclusão entre surdos e ouvintes só será efetiva com "a presença de profissionais surdos no contexto escolar, para que os alunos surdos tenham mais fluência de sua língua (Libras) e tenham contato com sua cultura, reconhecendo-se por meio do outro e expandindo a Libras garantida pela Lei n. 10.436, de 24 de abril de 2002".

Filipe de Souza Cardoso e Anna M. Canavarro Benite descrevem a estratégia sociointeracionista de planejamento e criação do design de um módulo instrucional para o ensino de ciências, apresentando "uma discussão sobre a educação de surdos pautada por questóes linguísticas, que envolvem o ensino da língua portuguesa e a língua de sinais", no artigo Estudos sobre planejamento e design de módulo instrucional para o ensino de ciências para surdos".

E, para discutir os "Recursos de tecnologia assistiva para alunas com surdez: sugestôes compartilhadas por uma bolsista Pibid”, Fátima Inês Wolf de Oliveira e Luciana Santana Cardoso apresentam um relato sobre alguns dados de observação e sugestôes que vêm sendo construídas a partir de indicativos e orientaçóes de uma bolsista do subprojeto Pedagogia Alfabetização, da Faculdade de Filosofia e Ciências da Unesp, em Marília-SP, e salientam que "a parceria colaborativa entre os integrantes da sala de aula, alunos, 
professora e possíveis auxiliares do trabalho docente também deve ser incentivada".

A citação "Nas últimas décadas, a legislação tem fortalecido o direito de todos ao ensino regular" dá título à entrevista concedida pela Profa. Clélia Brandão Alvarenga Craveiro ao Prof. Pítias Lobo, e sintetiza a argumentaçáo que essa experiente pedagoga apresenta quando discorre sobre o conjunto estratégico de açóes que têm fortalecido a inclusão de todos em escolas regulares de educação básica, no Brasil.

Para finalizar este dossiê, a Profa. Vivianne Fleury resenha a obra de Cristóvão Tezza, O filho eterno, afirmando que "de fato é, como está informado na folha de rosto, um romance. Contudo, calcada que é na experiência própria do autor, espécie de imagem que se reflete no espelho ad infinitum, esta é uma ficção autorreferente"; e conclui: "O filho eterno é uma narrativa literária, um livro sincero sobre experiência irremediável da paternidade. Ao fim e ao cabo, um pai é sempre um pai de seu filho".

Profa. Deise Nanci de Castro Mesquita Profa. Silvana Matias Freire Organizadoras 